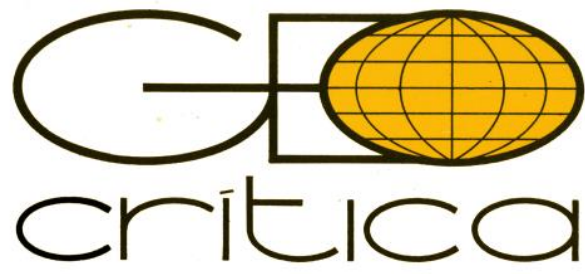

\title{
RECURSOS NA INTERNET PARA PESQUISA EM CIÊNCIAS HUMANAS: AS OBRAS FUNDAMENTAIS DA GEOGRAFIA
}

\author{
Sergio Aparecido Nabarro \\ Universidade Estadual de Londrina - UEL \\ sergionabarro@gmail.com
}

\begin{abstract}
Recursos na Internet para pesquisa em Ciências Humanas: as obras fundamentais da Geografia (Resumo)

Nas últimas três décadas se observa nas pesquisas em Ciências Humanas um retorno ao estudo das obras e autores considerados fundamentais. No caso específico da Geografia este regresso à leitura e análise das obras originais foi intensificado nos países latino-americanos a partir da metade dos anos 1980, mas atualmente ainda encontramos enormes dificuldades em relação ao acesso às obras. Por isso, o esforço de bibliotecas e institutos de documentação de vários países em digitalizar e disponibilizar seus acervos na internet é de grande valor para a realização de levantamentos bibliográficos. O objetivo deste artigo é apresentar ao leitor as principais plataformas digitais que disponibilizam parte ou a totalidade do seu acervo online, destacando aquelas que ofertam o maior número de obras vinculadas às Ciências Humanas.
\end{abstract}

Palavras-chave: Geografia; Obras Fundamentais; Pesquisa; Internet; Bibliotecas Digitais.

Internet resources for research in Human Sciences: the fundamental texts of Geography (Abstract)

In the last three decades, research in human sciences has seen a return to the study of works and authors considered fundamental. In the specific case of Geography, this return to reading and analyzing the original works has been intensified in Latin American countries since the mid-1980s, but today we still find enormous difficulties in relation to access to the works. For this reason, the effort of libraries and documentation institutes in several countries to digitize and make their collections available on the internet is of great value for the bibliographic survey. The purpose of this article is to introduce the reader to the main digital platforms that make part or all of his collection available online, highlighting those that offer the largest number of works related to the humanities.

Keywords: Geography; Fundamental Texts; Research; Internet; Digital Libraries. 


\section{Introdução}

Nas últimas duas décadas, temos observado uma expressiva diversificação dos temas pesquisados por geógrafos mundo a fora. Na Europa, por exemplo, as tradicionais pesquisas sobre formação do território, meio ambiente e urbanização, predominantes até anos 1990, atualmente dividem o protagonismo com investigações sobre Geografia e anarquismo, etnografia e identidade, expressões geográficas simbólicas, redes, discurso e política, Geografia e saúde pública entre outros temas relevantes. Na América Latina, as habituais pesquisas sobre colonialismo e formação territorial, industrialização em países subdesenvolvidos e meio ambiente e modo de vida, hoje convivem com investigações sobre cultura e reprodução territorial, mobilidade urbana, gênero, vida cotidiana na modernidade, populações tradicionais e impactos da expansão territorial do agronegócio. Mas, analisando grande parte dos pressupostos teóricos e metodológicos aos quais estas pesquisas se sustentam, é possível notar claramente um retorno à leitura das obras fundamentais da ciência geográfica, publicadas entre o final do século XIX e início do XX. Não se trata de mera transposição dos pressupostos da geografia tradicional para a compreensão do mundo contemporâneo, ao contrário, trata-se de recorrer aos clássicos, aos conceitos e teorias, para compreender como determinados fenômenos espaciais foram interpretados para depois formular uma compreensão mais adequada da realidade atual e, ao mesmo tempo, valorizar a historicidade do conhecimento geográfico.

Esse retorno ao estudo dos clássicos da Geografia está relacionado basicamente a dois fatores: 1) à crítica a interpretações equivocadas e/ou deturpadas de ideias de autores fundamentais desta ciência que por muito tempo foram reproduzidas na academia, a exemplo do enquadramento de intelectuais como Jacques Élisée Reclus, Paul Vidal de La Blache e Pierre Monbeig como geógrafos meramente descritivos, equívoco já refutado por vários trabalhos como os de Giblin ${ }^{1}$, Ferretti ${ }^{2}$, Nabarro ${ }^{3}$, Haesbaert et $a l^{4}$, Terry ${ }^{5}$ entre outros; 2) a popularização da internet, que contribuiu enormemente para o acesso aos catálogos e acervos de bibliotecas do mundo todo. Aliás, desde o início dos anos 2000, um grande esforço é realizado em bibliotecas e arquivos públicos de vários países para digitalizar seus acervos e disponibilizá-los ao público em sites oficiais, obedecendo à legislação referente à propriedade intelectual, aos direitos autorais e à transferência de obras para o domínio público.

Porém, muitos pesquisadores ainda não têm conhecimento da disponibilização destes materiais. Diante desta realidade, o objetivo deste artigo é informar ao leitor, sobretudo aos pesquisadores da Geografia, sobre os principais acervos online que permitem o acesso às obras fundamentais desta área do conhecimento, bem como de outros campos das ciências humanas. Para a elaboração deste texto, foram consultadas mais de 50 bibliotecas e arquivos virtuais existentes, porém foram selecionados apenas aqueles com um importante acervo de obras vinculadas às ciências humanas.

\footnotetext{
${ }^{1}$ Giblin, 1981 e 2005.

${ }^{2}$ Ferretti, 2014.

${ }^{3}$ Nabarro, 2020.

${ }^{4}$ Haesbaert et al., 2012.

5 Terry, 2009.
} 


\section{Gallica - Biblioteca Nacional da França}

Criada em 1997 para ser a versão digital da Biblioteca Nacional da França (BNF), o portal Gallica (figura 1) atualmente é uma das maiores bibliotecas virtuais do mundo. Seu acervo é composto por mais de 7 milhões de itens catalogados, entre livros (780.693), mapas (172.223), periódicos (4.618.242), manuscritos (185.318), partituras (54.220), imagens (1.470.315), vídeos (2.268), áudios (51.411) entre outros.

Figura 1. Portal Gallica

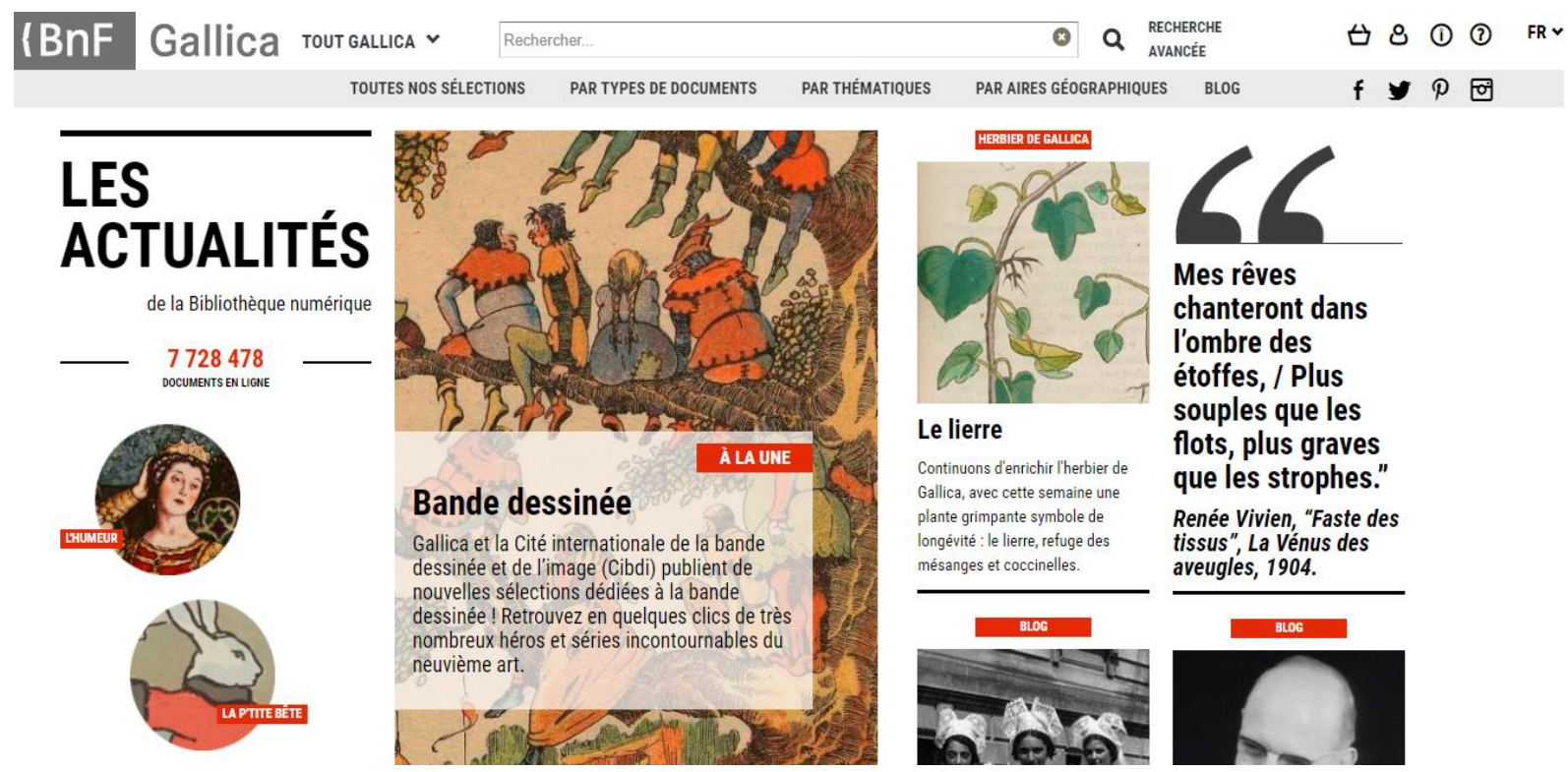

Fonte: <https://gallica.bnf.fr/accueil/fr/content/accueil-fr?mode=desktop>.

O catálogo pode ser acessado em língua francesa, alemã, inglesa, italiana e russa, mas além de obras nestes idiomas, a plataforma digital conta também com muitos itens originalmente publicados em português. Além disso, todo o acervo do portal é totalmente gratuito e pode ser acessado de qualquer lugar do mundo pelo endereço eletrônico <http://gallica.bnf.fr>.

Pela norma europeia, uma obra apenas entra em domínio público 70 anos após a morte do seu autor. Portanto, a Gallica dispõe majoritariamente de obras publicadas até 1949. Mas os itens disponibilizados que foram publicados posteriormente possuem autorizações prévias dos respectivos autores e/ou detentores dos direitos autorais.

Entre as obras com maior número de consultas e downloads estão: a versão original d' $O$ Contrato Social ou Princípios do Direito Político, de Jean-Jacques Rousseau, publicada originalmente em 1762; o manuscrito original do Discurso Sobre a Servidão Voluntária, elaborado pelo revolucionário francês Étienne de La Boétie em 1548; a primeira versão francesa do Manifesto do Partido Comunista de Karl Marx e Friedrich Engels, publicada em Paris no ano de 1882; e Discurso do Método, de autoria de René Descartes, de 1637. 
Especificamente em relação à Geografia, a plataforma digital disponibiliza em seu acervo obras raras, como o suplemento ${ }^{6}$ de 29 páginas com análises e dados estatísticos de Cuba, dos anos 1825 a 1829, elaborado por Alexander von Humboldt como um complemento da obra Ensaio Político sobre a Ilha de Cuba. São disponibilizados também mais de 30 mapas que ilustraram as obras originais do autor e a versão francesa de Cartas de Alexander von Humboldt a Varnhagem von Ense $e^{7}$ de 1860. Ainda sobre os intelectuais sistematizadores da ciência geográfica, o portal possui em seu acervo textos extremamente importantes, a exemplo de $A$ Configuração dos Continentes sobre a Superfície do Globo e suas Funções na História ${ }^{8}$, de Carl Ritter.

A partir de 2010, o portal Gallica, em parceria com a Biblioteca da Sorbonne, passou a disponibilizar para download os textos mais importantes de Paul Vidal de La Blache. Entre os mais acessados estão: a publicação original, de 1922, de Princípios de Geografia Humana, organizada por Emmanuel de Martonne; o Quadro da Geografia da França, de 1911, e os 33 cadernos originais de anotações do geógrafo (figura 2).

Figura 2. Páginas iniciais do caderno de anotações $n^{0} 1$ de Paul Vidal de La Blache

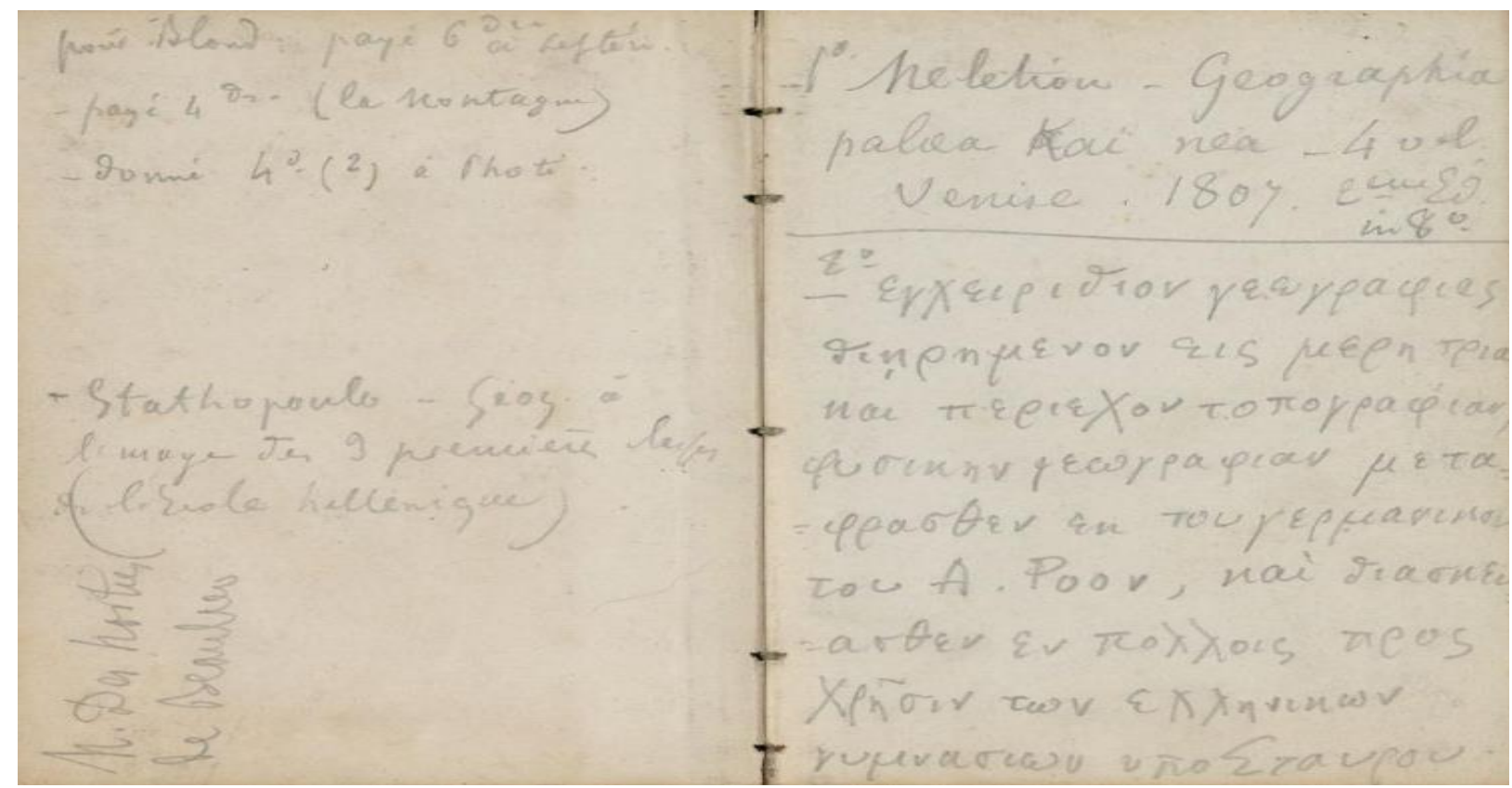

Fonte: $<$ https://nubis.univ-paris1.fr/ark\%3A/15733/3h5f\#?c=\&m=\&s=\&cv=\&xywh=-122\%2C$344 \% 2 \mathrm{C} 1386 \% 2 \mathrm{C} 1663>$.

Atualmente, muitos pesquisadores latino-americanos recorrem ao portal para acessar as obras originais do anarquista-geógrafo francês Jacques Élisée Reclus (1830-1905), um dos maiores intelectuais do século XIX, responsável por uma obra bastante extensa. Entre os escritos mais acessados deste autor estão os tomos de suas três grandes obras (os dois volumes de A Terra; os 19 volumes e o quadro estatístico da Nova Geografia Universal; e os três volumes de $O$ Homem e a Terra). Até o ano de 2020, o portal Gallica foi a plataforma digital com o maior acervo das obras originais de pensador ácrata. É possível localizar, portanto, muitos outros livros escritos por ele, além de centenas de artigos de sua autoria publicados nos mais

\footnotetext{
${ }^{6}<$ https://gallica.bnf.fr/ark:/12148/bpt6k10735067/f23.item>.

7 <https://gallica.bnf.fr/ark:/12148/bpt6k9780186k/f1.item>.

$8<$ https://gallica.bnf.fr/ark:/12148/bpt6k62824w?rk=21459;2>.
} 
importantes periódicos europeus do século XIX. Entre os mais acessados estão: Algumas palavras sobre História, ${ }^{9}$ publicado em 1894 na revista La Société Nouvelle; o panfleto Ao meu irmão, o camponês ${ }^{10}$, de 1899 (figura 3); e a Aula Inaugural do Curso de Geografia Comparada no Espaço e no Tempo ${ }^{11}$, de 1894.

Figura 3. Panfleto com a publicação original do Ao meu irmão, o camponês

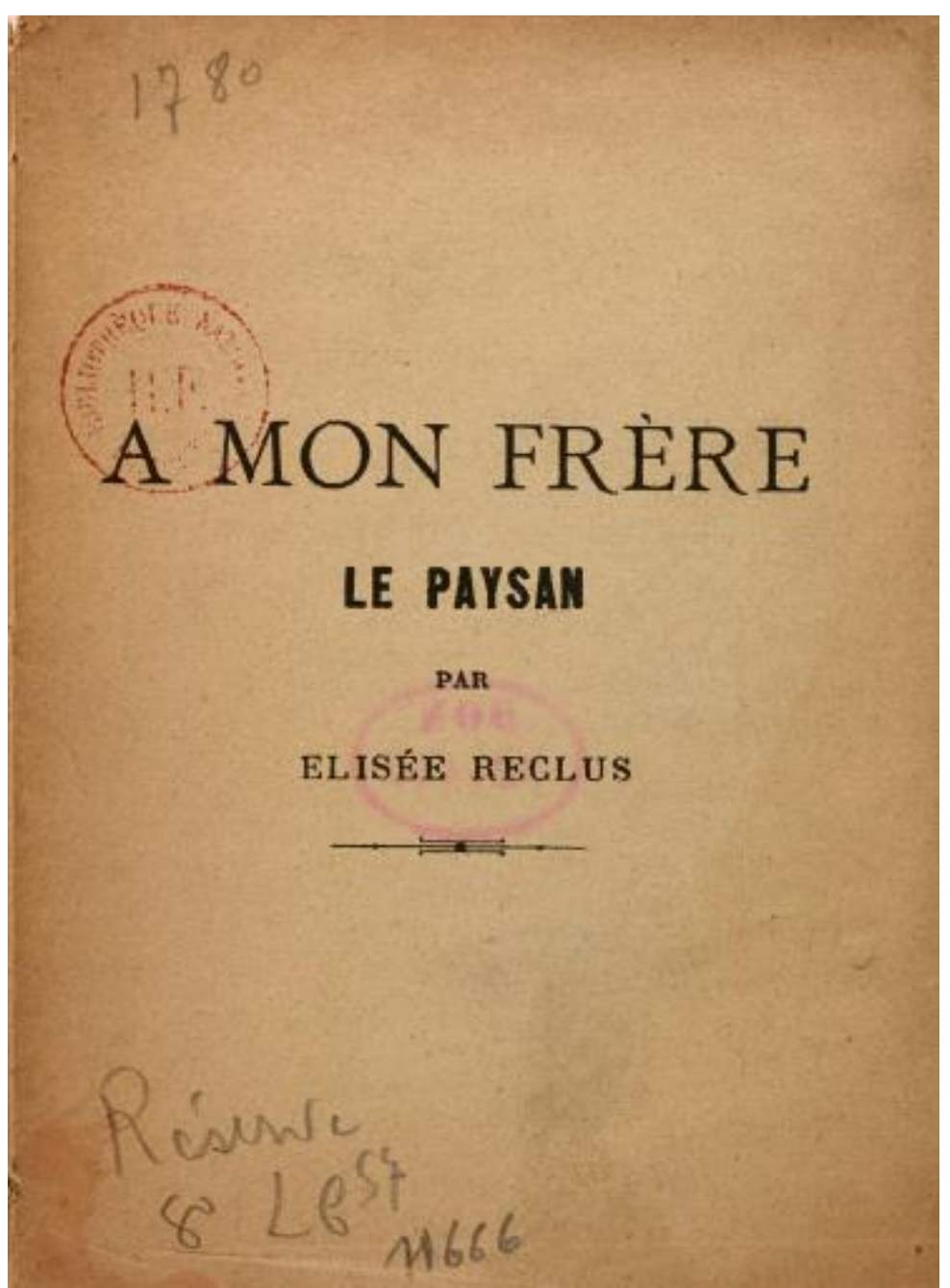

Fonte: 〈https://gallica.bnf.fr/ark:/12148/bpt6k1527697g/f5.item.r=paysan\%20paysan>.

Independentemente de qual for a área do conhecimento e o assunto da sua pesquisa, a plataforma Gallica deve ser consultada no levantamento bibliográfico. Seu acervo certamente oferecerá obras extremamente relevantes e de forma legal, segura e gratuita.

\footnotetext{
${ }^{9}<$ https://gallica.bnf.fr/ark:/12148/bpt6k660281/f2.item>.

$10<$ https://gallica.bnf.fr/ark:/12148/bpt6k1527697g\#>.

$11<$ https://gallica.bnf.fr/ark:/12148/bpt6k66026b?rk=450646;0>.
} 


\section{Biblioteca Digital Mundial}

A criação de uma biblioteca totalmente online cujo acervo seja composto com obras do mundo todo surgiu em 2005 quando o professor, historiador e bibliotecário do congresso estadunidense James Billington apresentou a proposta à Organização das Nações Unidas para Educação, Ciência e Cultura (UNESCO). O objetivo principal era criar uma plataforma digital de acesso rápido e fácil a informações sobre a história e a cultura de todos os países do mundo.

Em abril de 2009, a Biblioteca Digital Mundial (figura 4) foi lançada a partir de uma parceria entre a Biblioteca do Congresso Americano, a UNESCO e todos os Estados-membros da Organização das Nações Unidas (ONU). O portal pode ser visualizado em inglês, espanhol, português, francês, russo, chinês e árabe. Mas possui em seu acervo documentos em 145 idiomas.

Figura 4. Portal da Biblioteca Digital Mundial

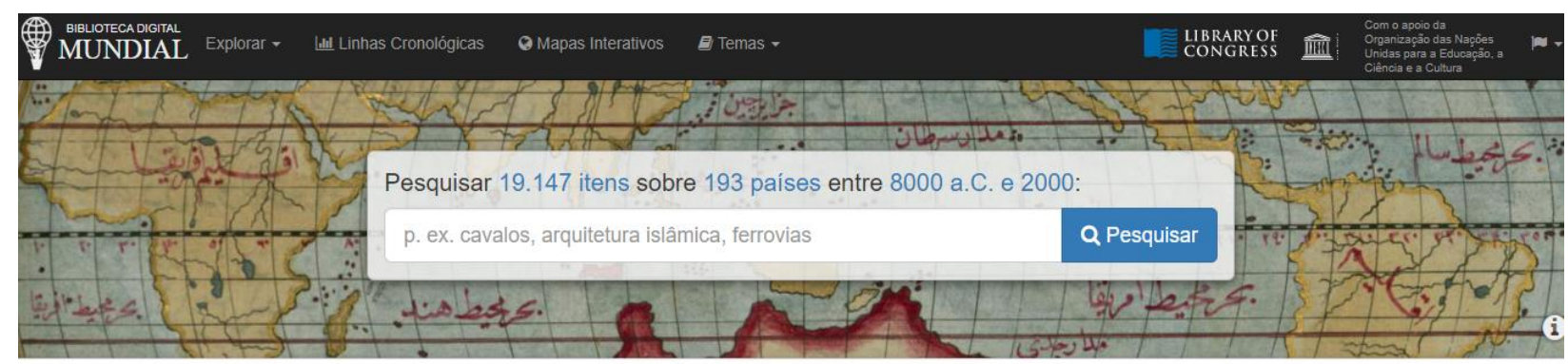

Itens apresentados >

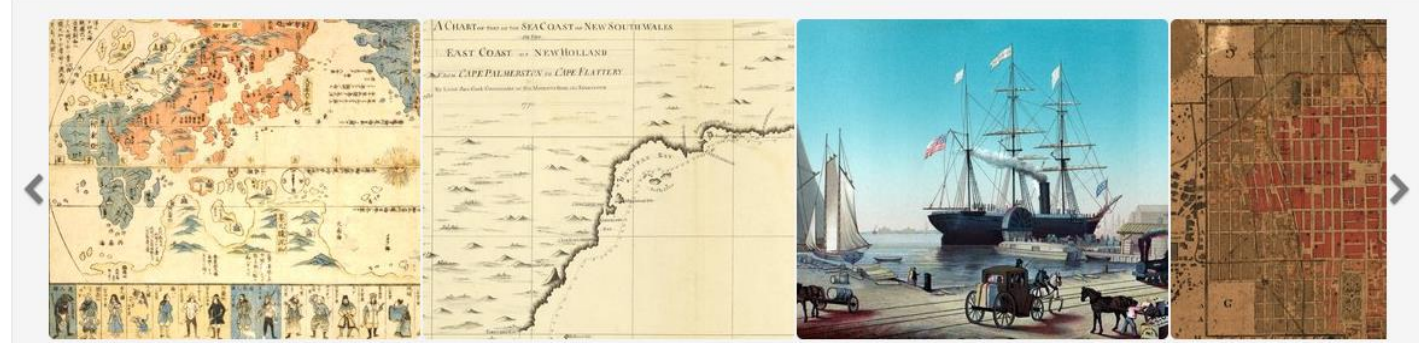

Fonte: <https://www.wdl.org/>.

Atualmente, o acervo da Biblioteca Digital Mundial é abastecido por mais de 158 instituições, de 60 países e oferece mais de um milhão de itens, entre livros (646.058), manuscritos (303.030), diários (69.198), fotografias (15.960), jornais (14.890), mapas (7.954), registros fonográficos (47) e filmes (38). No catálogo é possível encontrar desde fotografias de pinturas rupestres de 8.000 a.C. a livros publicados nos anos 2000 .

Entre os itens mais acessados estão: o Códice Sobre o Voo dos Pássaros ${ }^{12}$, elaborado por Leonardo da Vinci em 1505; a Carta de Cristóvão Colombo $^{13}$, escrita em 1493 na qual ele relata a sua viagem ao atlântico e anuncia a descoberta das "ilhas da Índia além do Ganges"; a Declaração de Independência dos Estados Unidos $^{14}$, de 1776; o manuscrito original da peça

\footnotetext{
$12<$ https://www.wdl.org/pt/item/19477/>.

$13<$ https://www.wdl.org/pt/item/90/>.

$14<$ https://www.wdl.org/pt/item/109/\#q=independencia+estados+unidos $>$.
} 
Hernani $^{15}$, elaborado pelo romancista francês Vitor Hugo em 1830; e o Talmude Babilônico ${ }^{16}$, o mais importante dos manuscritos hebreus do século III.

Especificamente sobre geografia, o catálogo apresenta inúmeras obras, com destaque para Geografia ${ }^{17}$, escrita por Ptolomeu no século II (figura 5), no qual o cientista compila todas as informações sobre o conhecimento geográfico do mundo greco-romano.

Figura 5. Primeira página do livro Geografia, de Ptolomeu

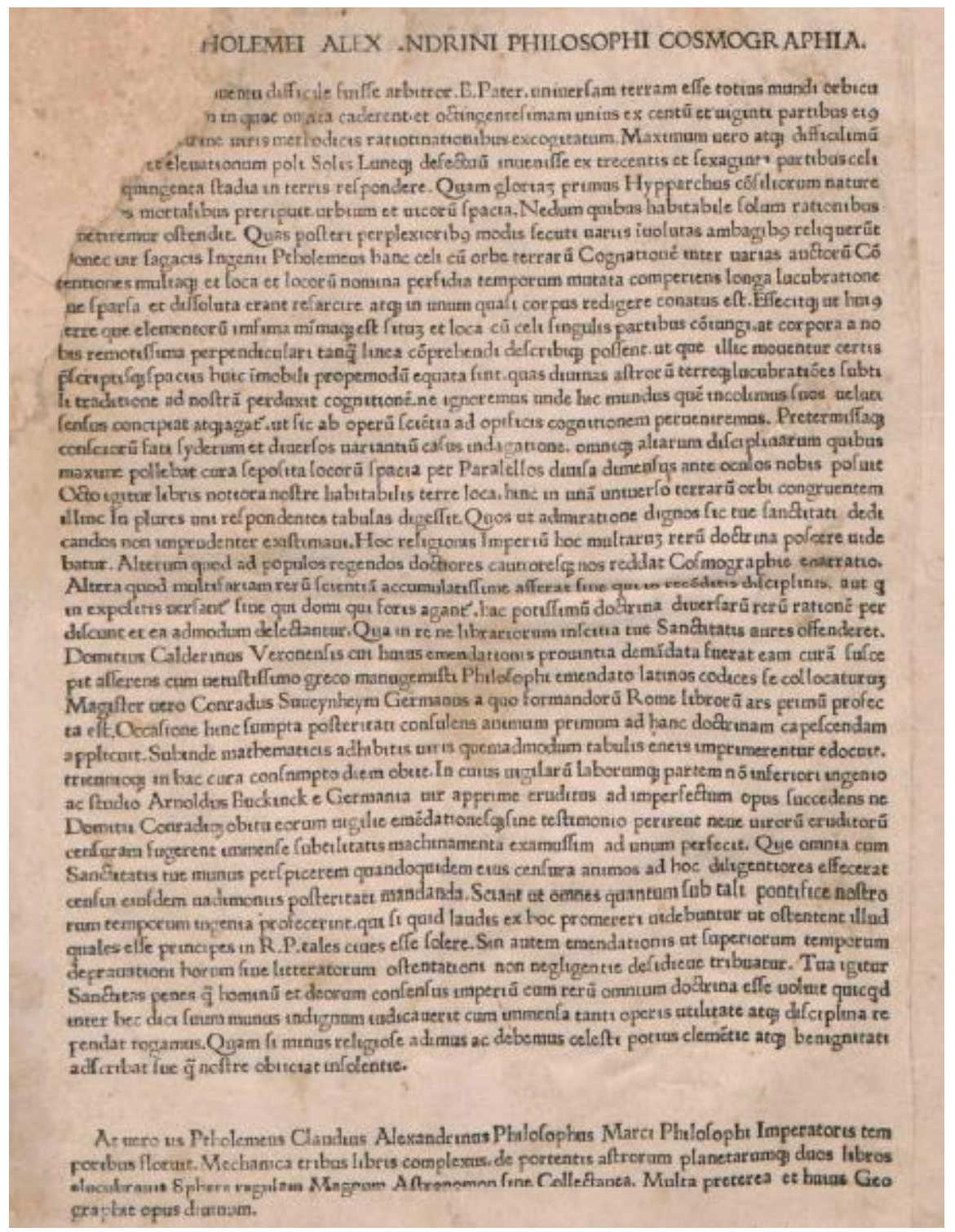

Fonte: <https://www.wdl.org/pt/item/10664/view/1/1/>.

\footnotetext{
$15<$ https://www.wdl.org/pt/item/14428/\#q=hernani+victor+hugo\&qla=pt $>$.

$16<$ https://www.wdl.org/pt/item/8910/\#q=Talmude+Babil\%C3\%B4nico>.

$17<$ https://www.wdl.org/pt/item/10664/>.
} 
Sobre geografia, ensino e cartografia também é possível encontrar no acervo importantes obras, como: a versão em búlgaro do Método de Peter Parley de falar sobre Geografia às Crianças ${ }^{18}$, de 1843, escrito originalmente em inglês por Samuel Goodrich em 1827, considerado o primeiro livro ilustrado para crianças na língua búlgara; o Mapa-múndi ${ }^{19}$ do século $\mathrm{XV}$, elaborado pelo cosmógrafo veneziano Giovanni Leardo em 1452; o Atlas de Battista Agnese ${ }^{20}$, renomado cartógrafo italiano do século XVI, elaborado em 1544 (figura 6); o livro Geografia Bíblica da Ásia Menor, Fenícia e Arábia ${ }^{21}$, escrita pelo alemão Ernst Friedrich Karl Rosenmüller em 1841; entre outras.

Figura 6. Páginas 13 e 14 do Atlas de Battista Agnese

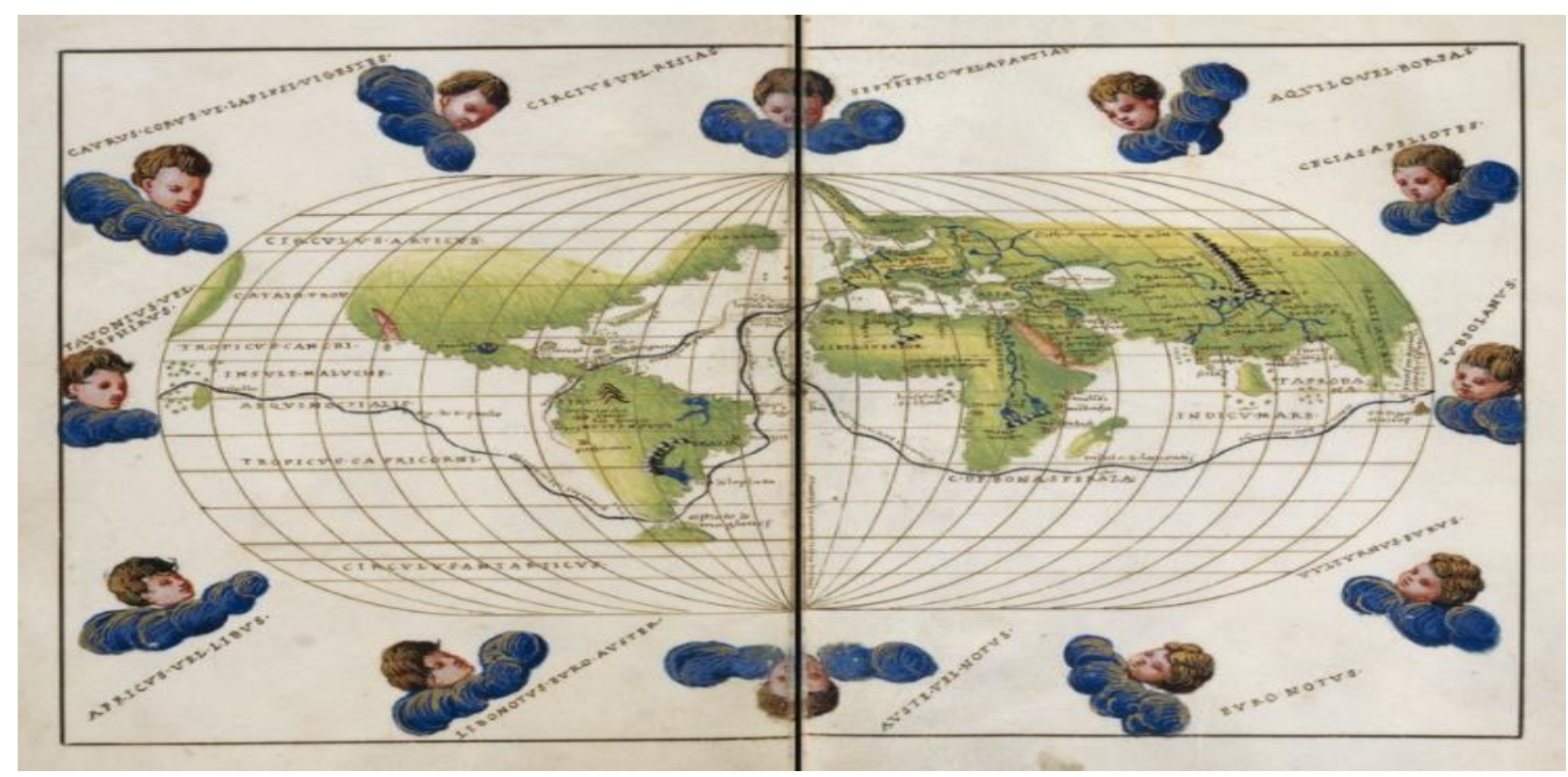

Fonte: <https://www.wdl.org/pt/item/7336/view/1/1/>.

Seja qual for o tema de pesquisa, a Biblioteca Digital Mundial é uma excelente opção para a realização de um minucioso levantamento bibliográfico porque, além de possuir um grande e valioso acervo de acesso gratuito, apresenta aos pesquisadores uma descrição detalhada, em vários idiomas, dos itens do catálogo.

\section{Biblioteca Digital Alemã}

Criada em 2012 para disponibilizar ao grande público o acesso rápido e gratuito ao patrimônio cultural e científico da Alemanha, a Biblioteca Digital Alemã possui um dos maiores acervos digitais do mundo, composto por mais de 35 milhões de objetos catalogados, sendo aproximadamente 11,5 milhões já digitalizados (figura 7). De acordo com seus gestores, a instituição recebe recursos financeiros dos governos federal, estadual e municipal, totalizando 2,6 milhões de euros anuais para sua manutenção.

\footnotetext{
$18<$ https://www.wdl.org/pt/item/4083/\#q=geografia\&qla=pt>.

$19<$ https://www.wdl.org/pt/item/6763/\#q=geografia\&page=3\&qla=pt $>$.

$20<$ https://www.wdl.org/pt/item/7336/>.

$21<$ https://www.wdl.org/pt/item/17236/\#q=geogr\%C3\%A1fico>.
} 
O portal pode ser acessado, em língua inglesa ou alemã, de qualquer lugar do mundo, por dispositivos conectados à internet.

Figura 7. Portal da Biblioteca Digital Alemã

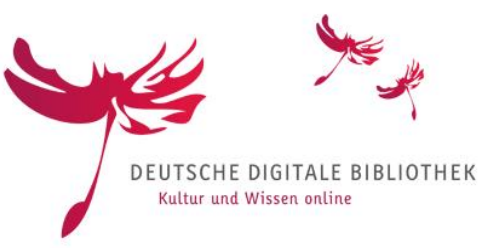

$35,298,083$ objects, including $11,583,317$ with digitised media
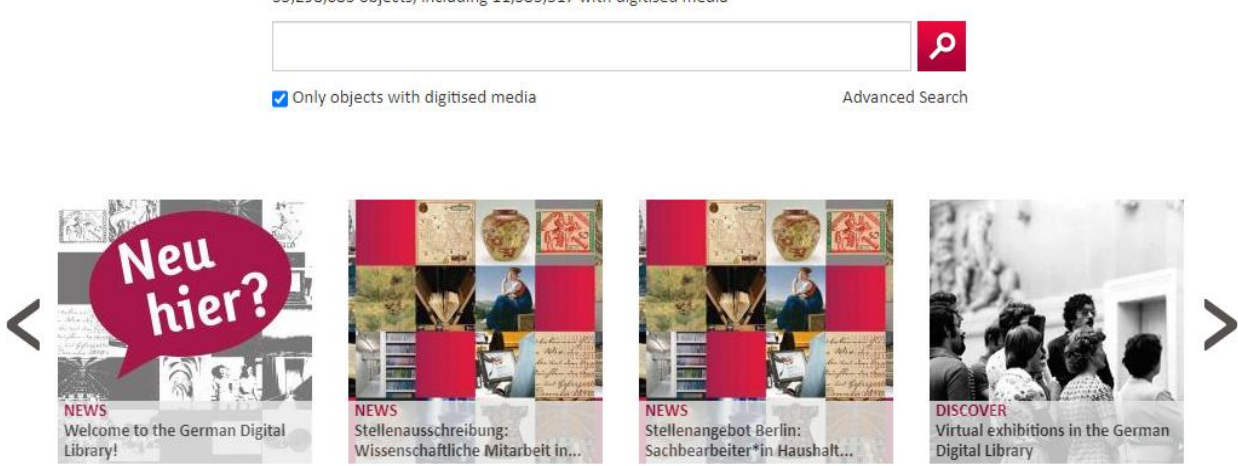

Fonte: <https://www.deutsche-digitale-bibliothek.de/>.

O acervo da biblioteca, alimentado por mais de 30.000 instituições culturais e de pesquisa da Alemanha, é considerado o mais seguro e confiável do mundo porque todas as obras digitais disponibilizadas possuem selo de autenticidade e atestação de autoria. Além disso, em respeito à legislação de direitos autorais e de propriedade intelectual europeia, todos os itens da biblioteca estão em domínio público ou possuem autorização dos autores para disponibilização na rede mundial de computadores.

O acervo atual é composto por livros, esculturas, pinturas, documentos históricos, fotografias, gravações em áudio e/ou vídeo e partituras. Entre os itens mais acessados do acervo estão: as Partituras Originais de Ludwig van Beethoven ${ }^{22}$, publicadas em 1830, três anos após a sua morte; o manuscrito da famosa música sacra Aus tiefer Not schrei ich zu dir ${ }^{23}$ (Das profundezas, eu clamo a ti), composta em 1724 por Johann Sebastian Bach; a publicação original em alemão do primeiro volume do livro O Capital $^{24}$, de Karl Marx, de 1867; os originais das Cartas de Immanuel Kant ${ }^{25}$, enviadas pelo filósofo a vários destinatários no final do século XVIII e publicadas originalmente em 1797; e a versão original do livro $O$ Mundo como Vontade e Representação ${ }^{26}$, de Arthur Schopenhauer, de 1819.

Especificamente sobre Geografia, a Biblioteca Digital Alemã possui o maior acervo de obras originais de Alexander von Humboldt (1769-1859), Carl Ritter (1779-1859), Friedrich Ratzel (1844-1904) e Heinrich Kiepert (1818-1899). Entre as mais acessadas estão justamente aquelas

\footnotetext{
$22<$ https://www.deutsche-digitale-bibliothek.de/searchresults?query=Beethoven+score $>$.

$23<$ https://www.deutsche-digitale-bibliothek.de/item/FAROKWIFVY26N374Y5EJJCWSM4KBGY5J>.

${ }^{24}<\mathrm{https}$ ///www.deutsche-digitale-bibliothek.de/item/F3A4GR6OFPDDPX2AY7GVR3RQGYLD5AOH>.

$25<$ https://www.deutsche-digitale-bibliothek.de/item/BN7O24L6S5H5VBWZ4WX6QLWMV6BBI2YP>.

$26<$ https://www.deutsche-digitale-bibliothek.de/item/Q3UNVR2OQ5IMGHWMSED2WSDKFGZV6W4M>.
} 
que marcaram o período da sistematização da ciência geográfica, com destaque para: os cinco volumes da obra $\operatorname{Cosmos}^{27}$, de Alexander von Homboldt, publicados entre 1845 e 1862, nos quais o autor reuniu quase todo o conhecimento produzido pela humanidade sobre o universo, apresentando um tratado sobre ciência e natureza (figura 8); e para os 19 tomos da monumental obra Geografia em Relação a Natureza e a História do Homem ${ }^{28}$, de Carl Ritter, publicados entre 1817 e 1859, nos quais o autor propõe o conceito de Erdkunde (o equivalente à Geografia na língua alemã) para compreender as contradições envolvendo a relação homem-natureza.

Figura 8. Publicação original do primeiro volume da obra Cosmos (1845)

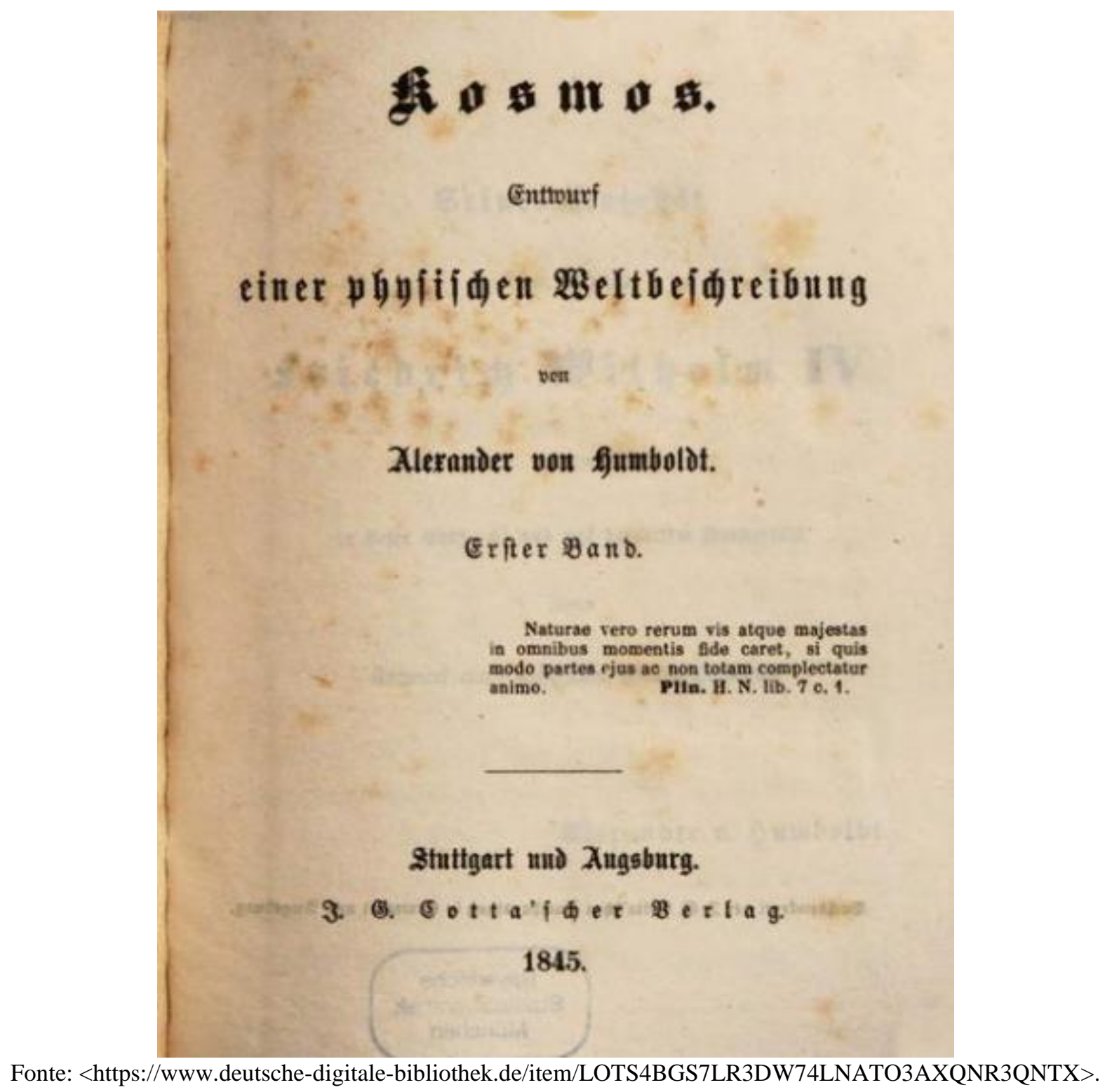

\footnotetext{
27 <https://www.deutsche-digitale-bibliothek.de/item/LOTS4BGS7LR3DW74LNATO3AXQNR3QNTX>.
}

$28<$ https://www.deutsche-digitale-bibliothek.de/item/P7Y2SCGXPKDXPOH3NYQ6OIUTZDWJ2DWQ>. 
A biblioteca também disponibiliza outros importantes trabalhos de geógrafos alemães, entre eles o texto original de A Colonização Europeia no Sul do Brasil ${ }^{29}$, de Leo Waibel (1888-1951), publicado em 1955 (figura 9), no qual o autor fornece grande contribuição para os estudos de geografia agrária no Brasil, e publicações de outros profissionais cuja temática adentrou ao debate geográfico alemão, como as obras do economista/geógrafo Johann Heinrich von Thünen (1783-1850) e do meteorologista/geofísico Alfred Wegener (1880-1930).

Figura 9. Publicação original de A Colonização Europeia no Sul do Brasil (1955)

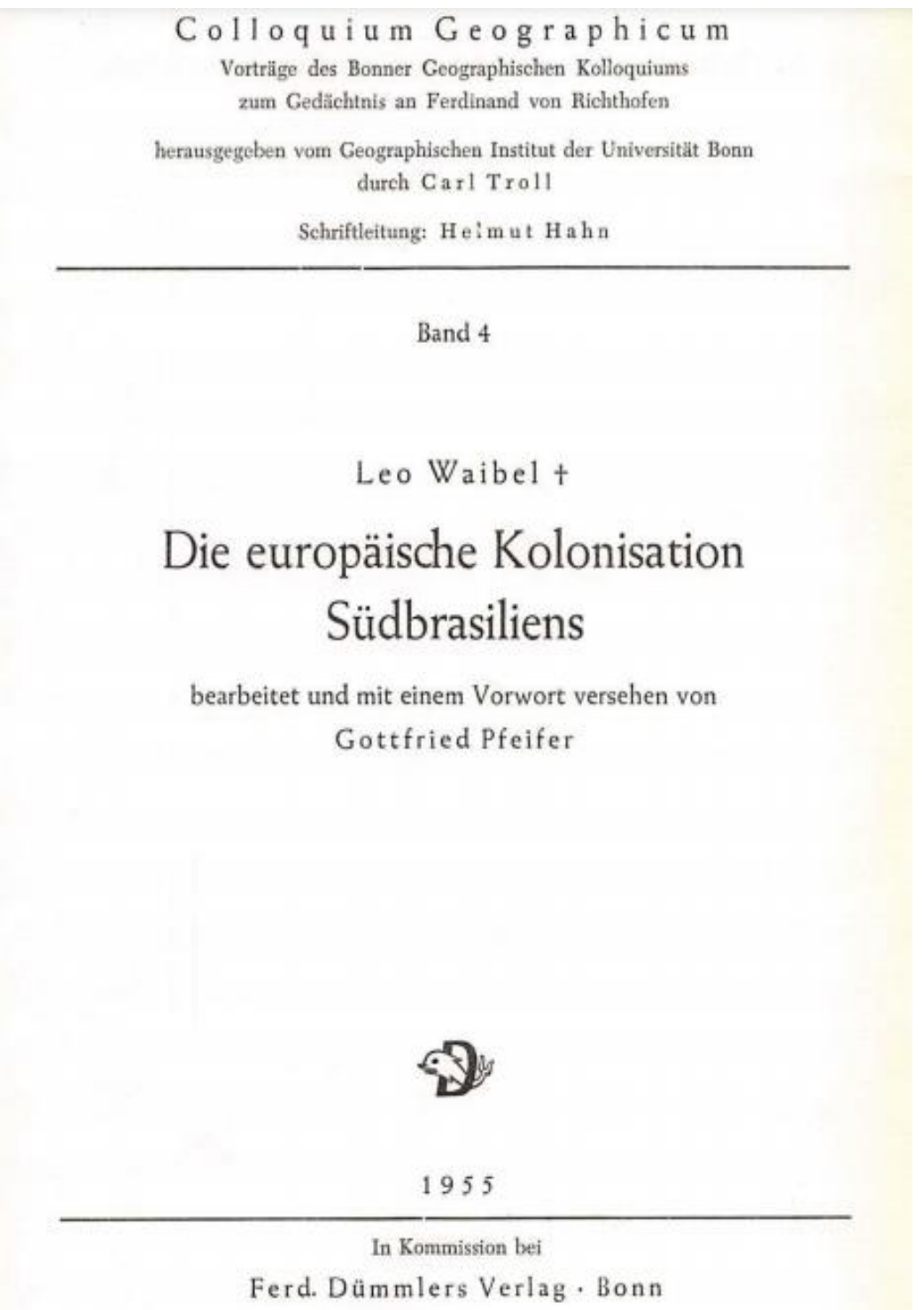

Fonte: 〈https://www.deutsche-digitale-bibliothek.de/item/XABE44MXVPLH6WBDDQ6BRZHGFS5CLIIY〉.

\footnotetext{
${ }^{29}$ 〈https://www.deutsche-digitale-bibliothek.de/item/XABE44MXVPLH6WBDDQ6BRZHGFS5CLIIY>.
} 
A Biblioteca Digital Alemã oferece uma gama de referências originais principalmente para pesquisadores da epistemologia das ciências sistematizadas no século XIX. Os geógrafos, sobretudo os estudiosos da história do pensamento geográfico e da geografia agrária, irão encontrar centenas de obras relevantes destas áreas. Já os investigadores das demais ciências humanas poderão encontrar os originais dos mais importantes escritos que influenciaram o pensamento social alemão e mundial.

\section{Biblioteca Digital Hispânica}

Criada em 2008 para ser a versão digital da Biblioteca Nacional da Espanha, a Biblioteca Digital Hispânica tem os seguintes objetivos: difundir o patrimônio cultural do país e garantir sua proteção; honrar o compromisso firmado com a União Europeia de contribuir para a criação de uma biblioteca digital do bloco; oferecer aos leitores e pesquisadores de todo o mundo uma ferramenta para facilitar o acesso ao conhecimento produzido em território espanhol; e ser um canal de cooperação entre as bibliotecas espanholas e latino-americanas.

De acordo com os gestores, em seu primeiro ano de funcionamento, a biblioteca digital recebeu recursos do Ministério da Indústria, Comércio e Turismo da Espanha. Posteriormente, os aportes financeiros para sua manutenção e para os projetos de digitalização foram dados também por entidades privadas.

Inicialmente, o acervo foi criado com aproximadamente 10.000 obras, selecionadas por especialistas de diversas áreas do conhecimento, com objetivo de expor na nova plataforma digital aquelas de maior relevância que integravam o acervo da Biblioteca Nacional da Espanha (figura 10). Atualmente, neste portal são disponibilizadas mais de 220.000 mil obras de todas as áreas do conhecimento e das artes, todas de acesso fácil, rápido e totalmente gratuito.

Figura 10. Portal da Biblioteca Digital Hispânica

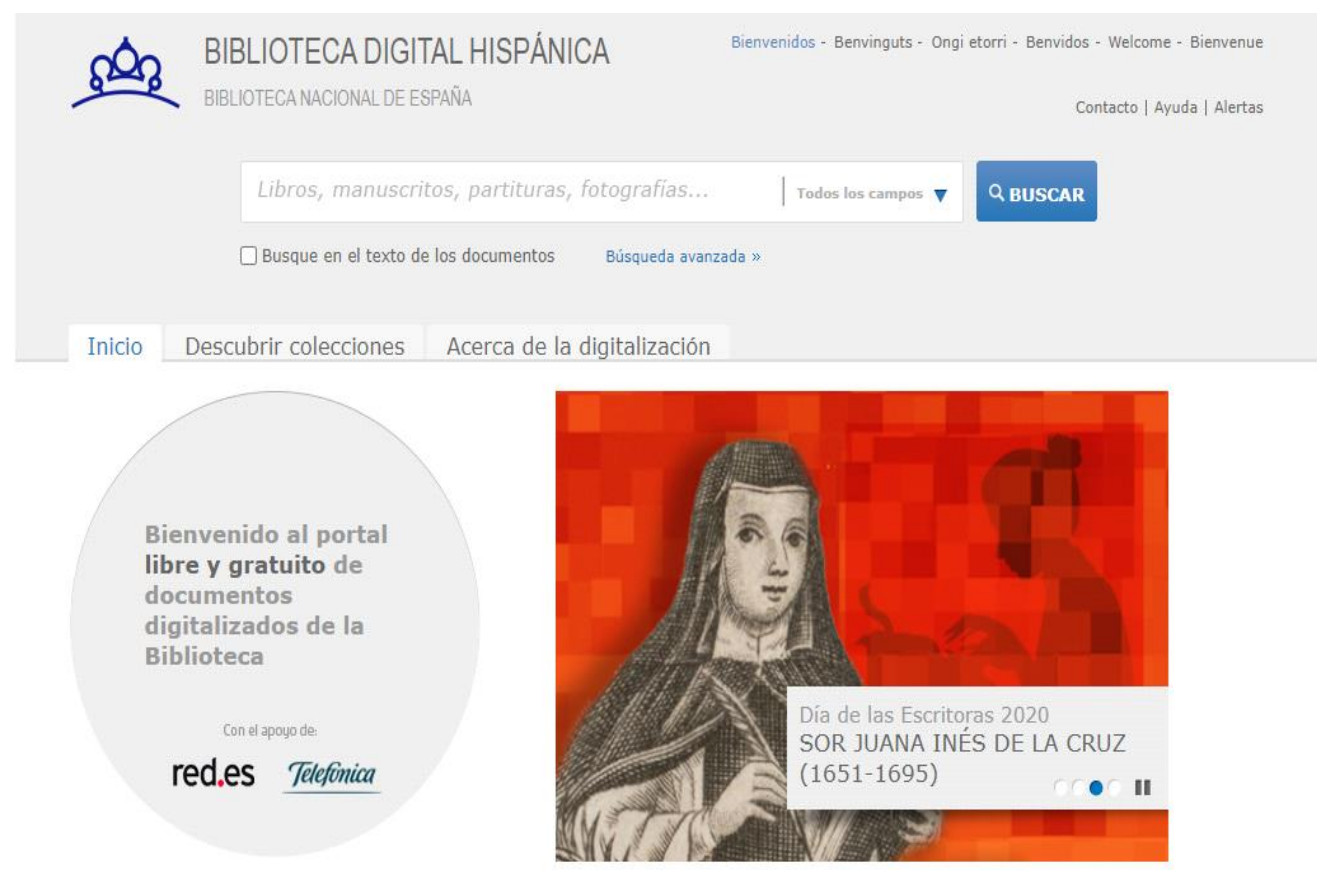

Fonte: <http://www.bne.es/es/Catalogos/BibliotecaDigitalHispanica/Inicio/index.html>. 
O acervo é composto por monografias (88.217), manuscritos (24.546), gravuras e fotografias (46.351), partituras (31.274), materiais cartográficos (12.009), áudios (20.1200) e periódicos (1.822). Todos os itens do acervo possuem descrição em vários idiomas (espanhol, inglês, francês, catalão, galego e basco).

De acordo com dados divulgados pela administração da plataforma, o portal já recebeu mais de 8 milhões de acessos, realizados por mais de 1 milhão de usuários de 60 países. Atualmente, é contabilizada uma média de 138.000 novos acessos mensais, realizados por 95.000 novos usuários. Entre os itens mais acessados estão: o tomo I da versão espanhola do livro A Filosofia do Espírito $^{30}$, do filósofo alemão Georg Wilhelm Friedrich Hegel, publicada em Madri em 1907; o Compendio da Obra A Riqueza das Nações de Adam Smith ${ }^{31}$, publicado por Carlos Martinéz de Irujo em 1814; a tradução espanhola do Tratado de Trigonometria ${ }^{32}$, de Joseph Alfred Serret, de 1879; o Primeiro Romance Cigano ${ }^{33}$, publicado em 1929 por Federico García Lorca, considerado um dos mais importantes poetas/dramaturgos da Espanha e uma das primeiras vítimas da guerra civil, assassinado em 1936; e a versão em língua inglesa das Aventuras de Dom Quixote de la Mancha ${ }^{34}$, de Miguel de Cervantes Saavedra, de 1858.

De acordo com o quadro estatístico da plataforma, as obras relacionadas à geografia mais acessadas em 2020 foram: a versão em espanhol do texto O Futuro dos Nossos Filhos ${ }^{35}$, de Jacques Élisée Reclus, publicada em 1900 em Barcelona; os manuscritos dos Tratados Geográficos e Astronômicos ${ }^{36}$, datados entre 1501 e 1700, fragmentos extraídos de várias obras de autores como Dionisio Periegetes, Rodrigo Dosma Delgado, João Baptista Lavanha e Nicephorus Blemmida; a publicação original do livro Notas para o Estudo da Geografia ${ }^{37}$, de José Muro y López-Salgado, de 1902; e a versão em espanhol do Atlas Geográfico e Físico da Nova Espanha ${ }^{38}$ (figura 11), publicado em 1827, de autoria de Alexander von Humboldt.

\footnotetext{
$30<$ http://bdh-rd.bne.es/viewer.vm?id=0000253655\&page $=1>$.

$31<$ http://bdh-rd.bne.es/viewer.vm?id=0000132821\&page $=1>$.

$32<$ http://bdh-rd.bne.es/viewer.vm?id=0000218127\&page $=1>$.

$33<$ http://bdh-rd.bne.es/viewer.vm?id=0000200836\&page $=1>$.

$34<$ http://bdh-rd.bne.es/viewer.vm?id=0000250696\&page $=1>$.

$35<$ http://bdh-rd.bne.es/viewer.vm?id=0000174721\&page $=1>$.

$36<$ http://bdh-rd.bne.es/viewer.vm?id=0000042276\&page $=1>$.

$37<$ http://bdh-rd.bne.es/viewer.vm?id=0000245484\&page $=1>$.

$38<$ http://bdh-rd.bne.es/viewer.vm?id=0000001777>.
} 
Figura 11. Versão em espanhol do Atlas Geográfico e Físico da Nova Espanha

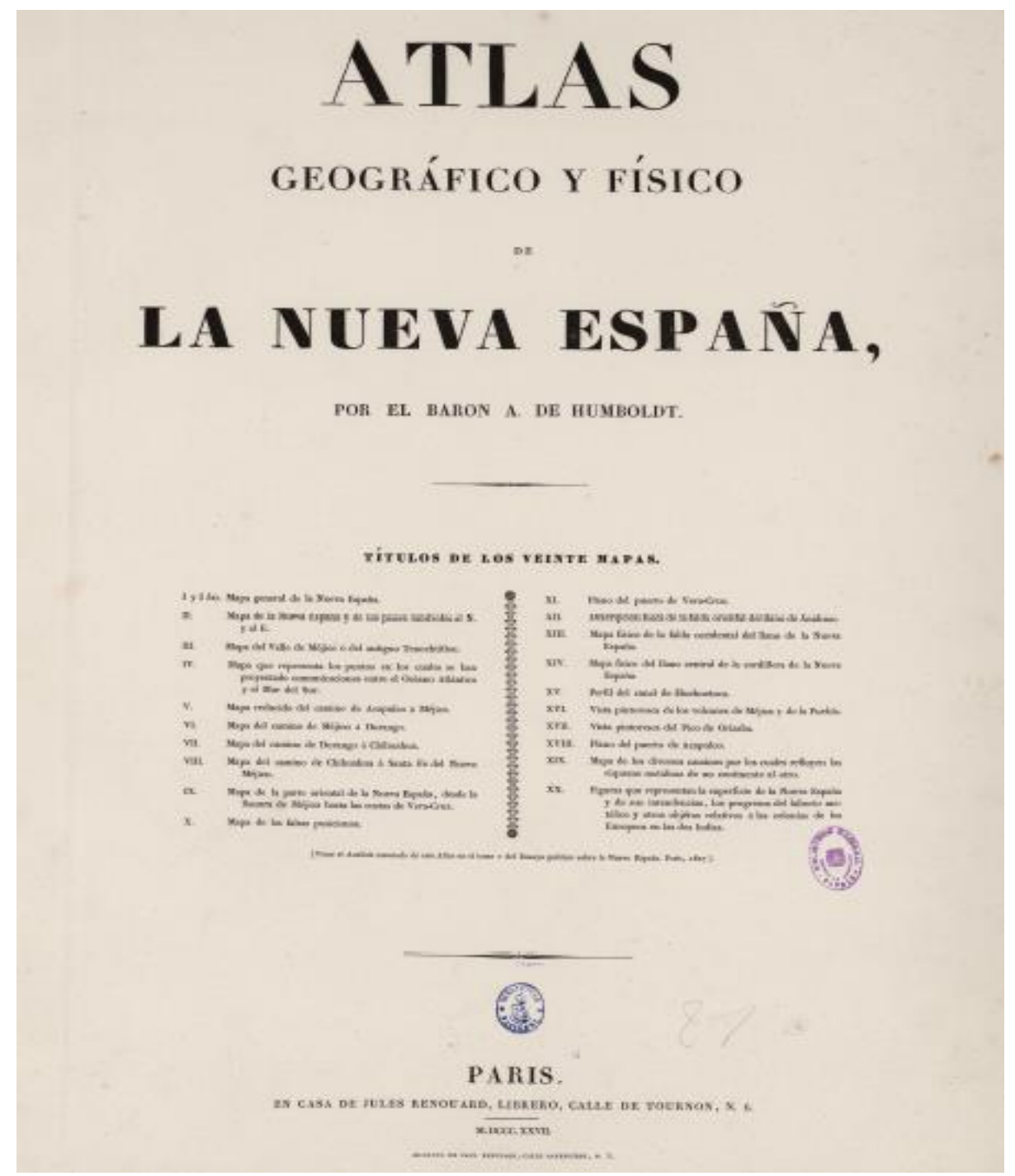

Fonte: <http://bdh-rd.bne.es/viewer.vm?id=0000001777>.

A Biblioteca Digital Hispânica é uma ótima opção para pesquisadores de temas relacionados às diversas áreas das Ciências Humanas. Além de oferecer um variado acervo e disponibilizar gratuitamente importantes obras em suas versões na língua espanhola, oferece uma das maiores quantidades de livros, mapas e manuscritos em português fora dos países lusófonos.

\section{Instituto Internacional de História Social (IISH)}

Criado em 1935 pelo historiador e cientista político holandês Nicolaas Wilhelmus Posthumus (1880-1960), o IISH é um dos maiores, mais antigos e mais importantes institutos de pesquisa em ciências humanas do mundo. Sediado em Amsterdam e vinculado a Academia Real Holandesa de Artes e Ciências (KNAW), o instituto possui o mais completo acervo sobre história econômica e história do trabalho da Europa.

Quando foi criado, o objetivo do IISH era proteger os registros alusivos à luta dos operários e de outros movimentos sociais europeus das ações de destruição de documentos promovidas pelo regime nazista alemão. Atualmente, seu acervo é composto por mais de um milhão de 
Recursos na Internet para pesquisa em Ciências Humanas: as obras fundamentais da Geografia

documentos, livros, manuscritos e periódicos que registram a história das organizações sindicais, anarquistas e comunistas da Europa. Além disso, possui um dos maiores acervos documentais sobre a Guerra Civil Espanhola e a Revolução Russa.

Todos os itens do catálogo do IISH podem ser consultados online, em inglês ou holandês, no portal do instituto (figura 12). Mas para receber uma cópia em PDF é preciso fazer uma solicitação no site e efetuar o pagamento, que pode ser feito de qualquer lugar do mundo via cartão de crédito. Após o pagamento, o documento é enviado por e-mail em até 48 horas.

Figura 12. Portal do Instituto Internacional de História Social (IISH)

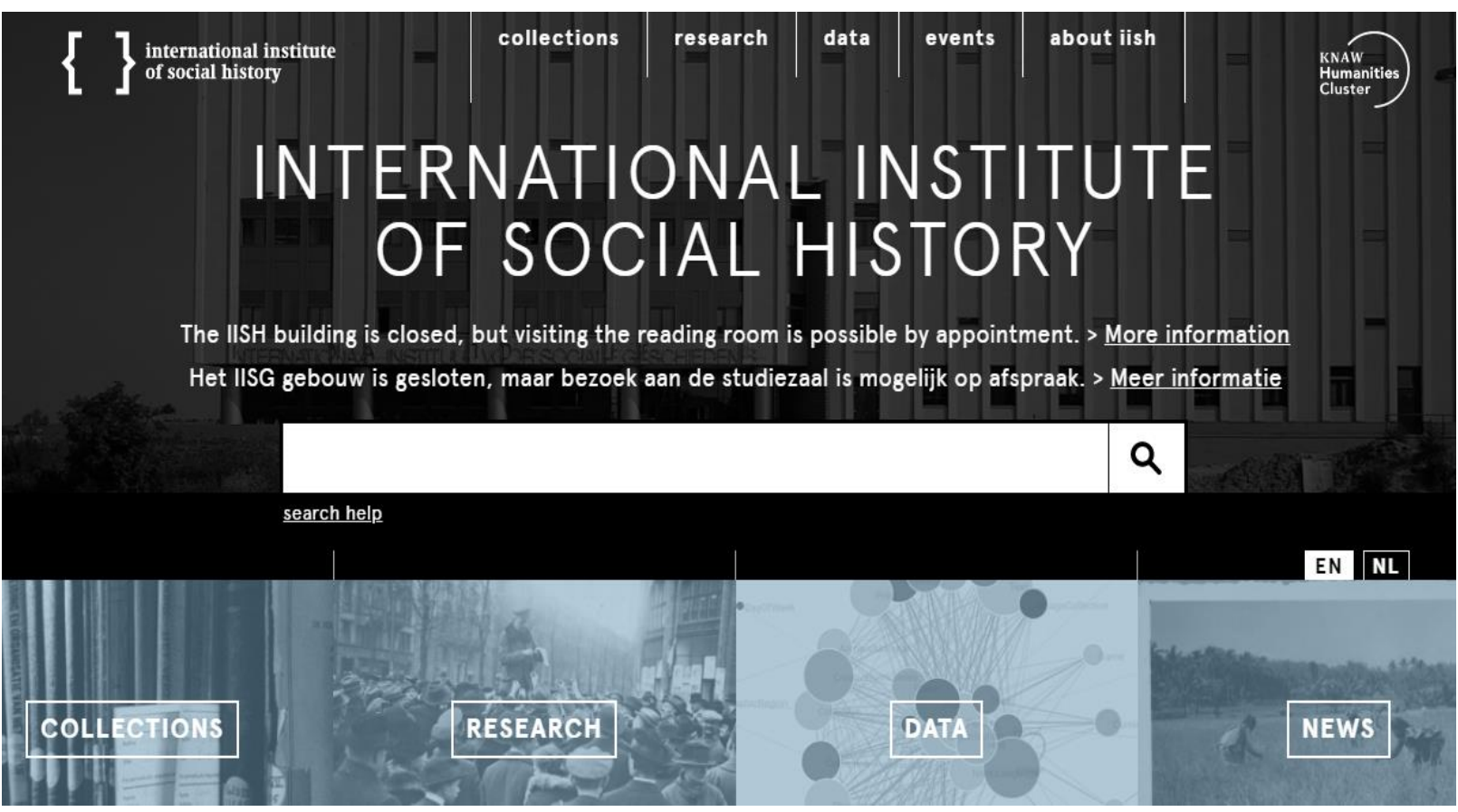

Fonte: <https://iisg.amsterdam/en>.

A plataforma recebe anualmente mais de um milhão de acessos provenientes de mais de 70 países. Entre os itens mais solicitados do catálogo estão: os manuscritos originais de $O$ Capital $^{39}$ e do Manifesto Comunista ${ }^{40}$ (figura 13) de Karl Marx; a carta de membro de Mikhail Bakunin como integrante da Liga Internacional da Paz e da Liberdade ${ }^{41}$; o livro Obras Completas de Voltaire ${ }^{42}$, publicado em 1876; e a coleção de Cartas Inéditas de Piotr Kropotkin a James Guillaume $^{43}$, de 1911.

\footnotetext{
$39<\mathrm{https}$ ://search.iisg.amsterdam/Record/698023>.

$40<$ https://search.iisg.amsterdam/Record/698075>.

$41<$ https://hdl.handle.net/10622/ARCH00018.69>.

$42<$ https://search.iisg.amsterdam/Record/1216922>

$43<$ https://search.iisg.amsterdam/Record/359364>.
} 
Figura 13. Página do manuscrito do Manifesto Comunista, de 1847

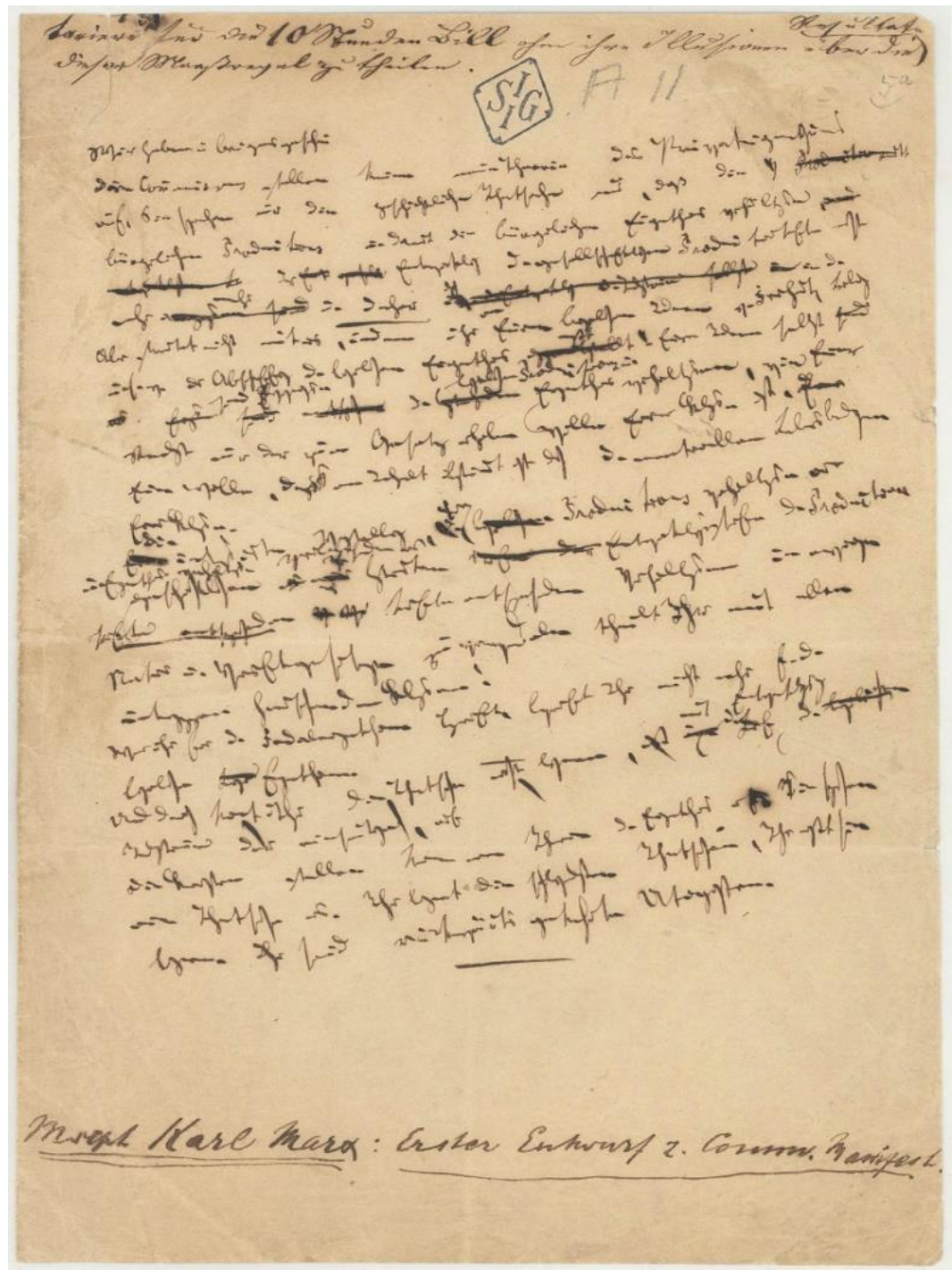

Fonte: 〈https://search.iisg.amsterdam/Record/698075>.

O IISH oferece um vasto acervo para pesquisas sobre a história do pensamento geográfico europeu do século XIX. Entre os itens mais acessados estão: a publicação original do texto $O$ que a Geografia deve ser ${ }^{44}$, escrito por Piotr Kropotkin em 1885; a primeira publicação do livro A Terra e a Evolução Humana ${ }^{45}$, de 1922, do historiador Lucien Febvre, considerado um dos continuadores das ideias de Paul Vidal de La Blache; e o texto Desenvolvimento da Liberdade no Mundo ${ }^{46}$ apontado como o primeiro escrito de Jacques Élisée Reclus, elaborado entre 1849 e 1850, mas publicado apenas em 1925, vinte anos após a morte do autor, no periódico anarquista Le Libertaire (figura 14).

\footnotetext{
$44<$ https://search.iisg.amsterdam/Record/383938>.

$45<$ https://search.iisg.amsterdam/Record/336667>.

$46<$ https://search.iisg.amsterdam/Record/ARCH01170>.
} 
Figura 14. Capa do periódico anarquista Le Libertaire, de 28 de agosto de 1925

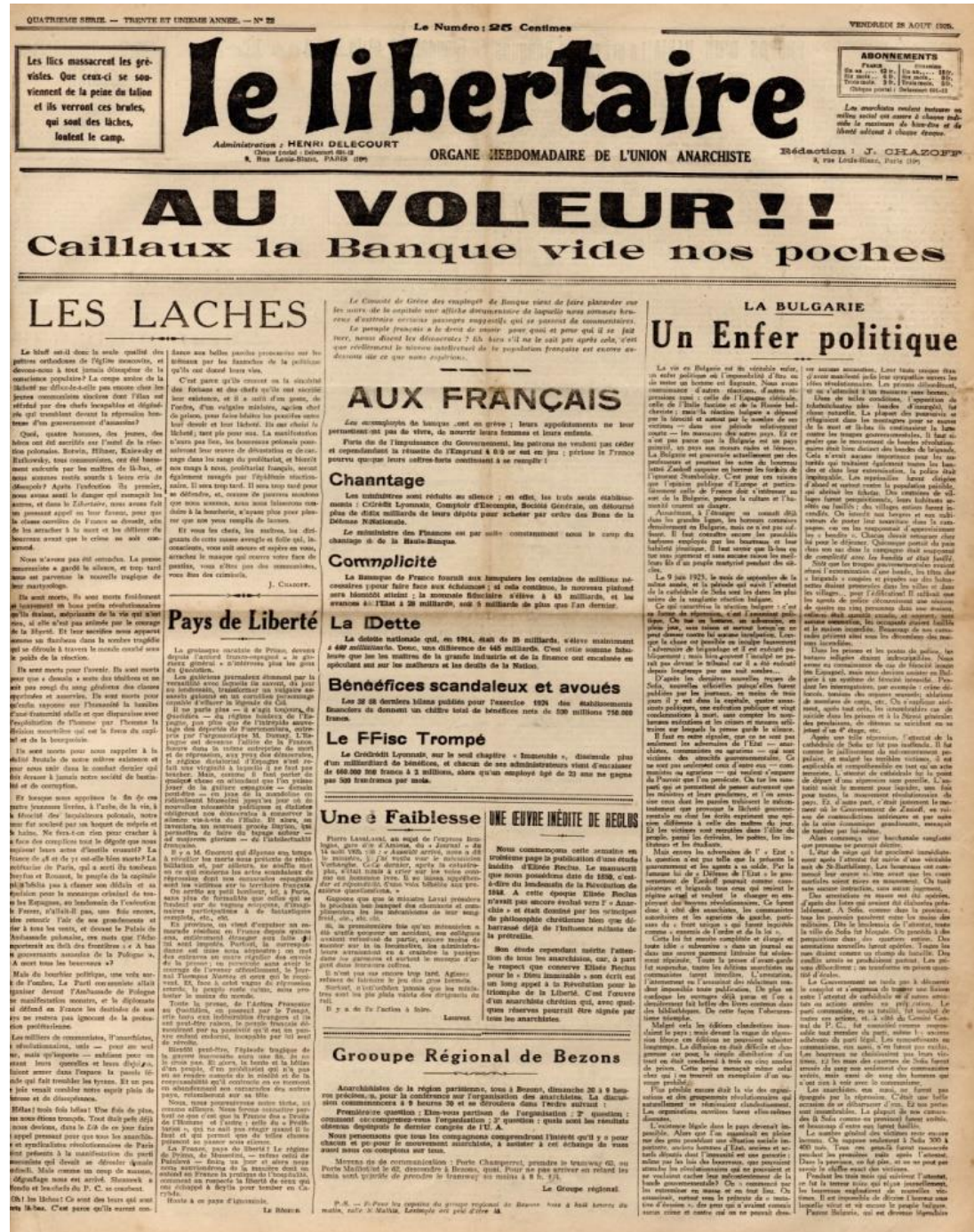

Fonte: <https://search.iisg.amsterdam/Record/ARCH01170>.

Especializado também em periódicos, o portal do Instituto Internacional de História Social de Amsterdam está certamente entre as melhores opções para a realização de levantamentos bibliográficos e para a localização dos textos mais importantes sobre as lutas sociais dos séculos XIX e XX no mundo todo. Mesmo que as obras do seu acervo não sejam de acesso gratuito, o custo da digitalização é acessível e compensado pela comodidade em receber o documento solicitado no seu e-mail em apenas algumas horas.

\section{Projeto Gutenberg}

Fundado em 1971 pelo escritor e analista de sistemas Michael Stern Hart, o inventor do e-book, o Projeto Gutenberg é a biblioteca digital mais antiga do mundo e o objetivo da sua criação foi promover o acesso rápido e gratuito à literatura produzida no mundo (figura 15). Atualmente, a biblioteca digital é administrada por voluntários, entre eles professores de diversas 
universidades, e seu acervo de e-books é totalmente gratuito e cumpre todas as exigências das legislações americana e europeia de propriedade intelectual e de direitos autorais.

A digitalização das obras é realizada em parceria com instituições e voluntários do mundo todo, mas a disponibilização das obras no portal apenas é realizada após análise e curadoria de pesquisadores capacitados de diversas áreas do conhecimento.

Figura 15. Portal do Projeto Gutenberg

\begin{tabular}{|c|c|c|c|}
\hline Project & About - & Search and Browse - & Help - \\
\hline Gutenbers & Quick search & Gol & Donation PayPal \\
\hline
\end{tabular}

\author{
Welcome to Project Gutenberg \\ Project Gutenberg is a library of over 60,000 free eBooks
}

Choose among free epub and Kindle eBooks, download them or read them online. You will find the world's great literature here, with focus on older works for which U.S copyright has expired. Thousands of volunteers digitized and diligently proofread the eBooks, for you to enjoy.

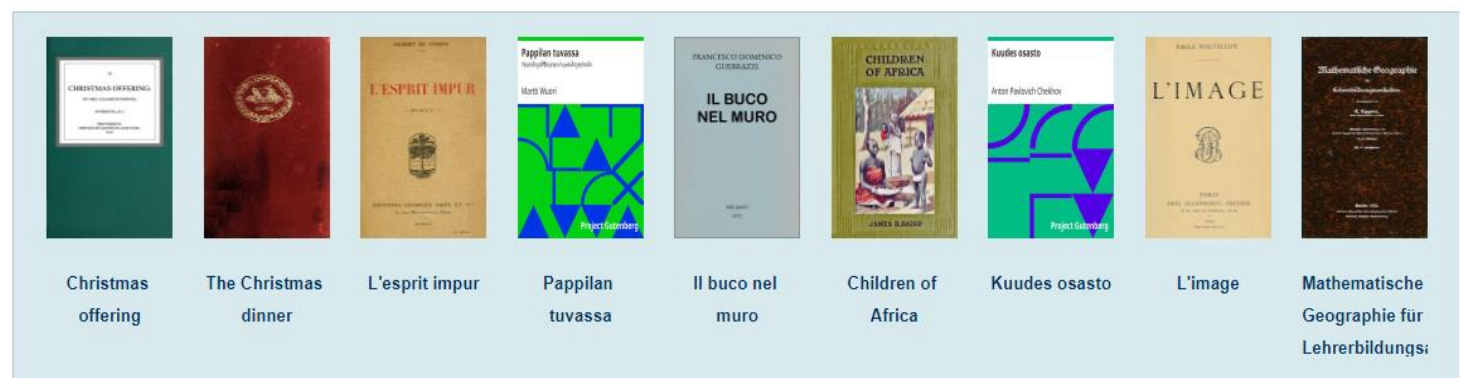

Fonte: <https://www.gutenberg.org/>.

O acervo é composto por mais de 60.000 livros gratuitos para download ou para leitura online. De acordo os dados fornecidos pela plataforma, apenas no mês de novembro de 2020 o site recebeu mais de 5 milhões de acessos, provenientes de 112 países.

Mensamente, os administradores da plataforma divulgam os e-books mais acessados pelos usuários. Até o dia 21 de dezembro de 2020, os livros com maior número de downloads foram: a primeira versão, publicada em 1842, de $O$ Cântico de Natal $^{47}$, do romancista inglês Charles Dickens; a publicação original, de 1813, de Orgulho e Justiça ${ }^{48}$, da escritora inglesa Jane Austen; o romance gótico Frankenstein ${ }^{49}$, de autoria da dramaturga Mary Shelley, de 1818; a reedição, de 2008, das Aventuras de Alice no País das Maravilhas ${ }^{50}$, obra originalmente escrita por Lewis Carroll em 1865; e a edição de 2001 do livro Moby Dick ${ }^{51}$, obra mais conhecida do ensaísta estadunidense Herman Melville, cuja publicação original é de 1851.

Embora a maior parte dos usuários do portal busque as mais famosas obras da literatura inglesa, a plataforma também oferece um amplo acervo de obras para pesquisa em ciências humanas. Especificamente sobre Geografia, o portal disponibiliza as principais obras de Jacques Élisée

\footnotetext{
$47<$ https://dev.gutenberg.org/ebooks/46>.

$48<$ https://dev.gutenberg.org/ebooks/1342>.

$49<\mathrm{https}$ ://dev.gutenberg.org/ebooks/84>.

$50<\mathrm{https}$ ://dev.gutenberg.org/ebooks/11>.

$51<\mathrm{https}$ ://dev.gutenberg.org/ebooks/2701>.
} 
Reclus $^{52}$, algumas com traduções para as línguas inglesa e espanhola; os três volumes de $A$ Geografia de Estrabão ${ }^{53}$ (figura 16), obra originalmente escrita em 17 tomos no século I; o primeiro volume da versão em inglês de $\operatorname{Cosmos}^{54}$, de Alexander von Humboldt; o livro Influências do Ambiente Geográfico, de Ellen Churchill Semple, entre outras obras consideradas fundamentais da ciência geográfica.

Figura 16. Primeiro volume de A Geografia de Estrabão

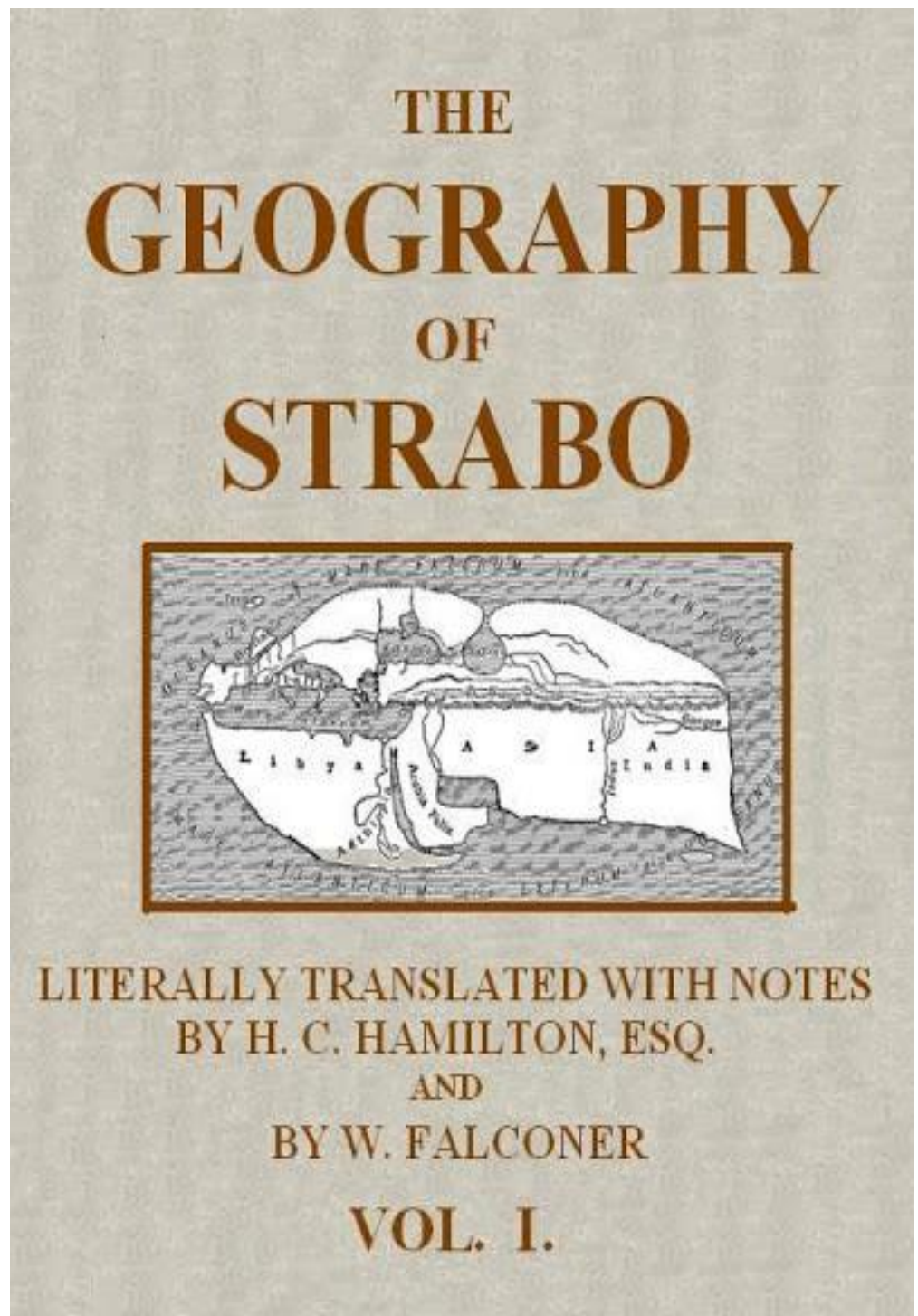

Fonte: 〈https://www.gutenberg.org/ebooks/44884>.

Entre os acervos das bibliotecas digitais analisados até aqui, a do Projeto Gutenberg é a que possui o maior número de obras de Geografia publicadas no século XX. Assim, podem recorrer ao seu catálogo não só os pesquisadores de temas relacionados à história do pensamento geográfico, mas investigadores de todos os temas desta área do conhecimento.

\footnotetext{
$52<$ https://dev.gutenberg.org/ebooks/search/?query=\%C3\%89lis\%C3\%A9e+Reclus\&submit_search=Go\%21>.

$53<$ https://dev.gutenberg.org/ebooks/author/42968>.

$54<$ https://www.gutenberg.org/ebooks/14565>.
} 


\section{Considerações Finais}

O confinamento da população e o fechamento temporário de bibliotecas, universidades e institutos de pesquisa em várias partes do mundo, promovidos pela pandemia da COVID-19, contribuíram para o aumento das pesquisas utilizando a internet como principal ferramenta para o levantamento bibliográfico. Mas este contexto também foi importante para aumentar e popularizar a leitura e a pesquisa online das obras consideradas fundantes das ciências e das artes. Segundo dados divulgados pelas bibliotecas digitais citadas neste artigo, durante os primeiros seis meses da pandemia houve um aumento médio de $62 \%$ no número de acessos às plataformas. Neste mesmo período, o número de downloads de livros digitais superou os anos de 2018 e 2019 somados.

Outro elemento importante a ser destacado é que a nova realidade imposta pela pandemia aos pesquisadores, principalmente os vinculados às ciências humanas, intensificou ainda mais o movimento de retorno à leitura e análise das obras fundamentais de áreas do conhecimento como História, Geografia, Sociologia e Antropologia. No caso específico da Geografia, os escritos de Jacques Élisée Reclus, Alexander von Humboldt, Carl Ritter e Paul Vidal de La Blache são atualmente os mais procurados. Mas é possível perceber também um aumento nas buscas por obras consideradas marcantes do período de renovação teórico-metodológica desta ciência, publicadas entre as décadas de 1960 e 1970.

Esperamos com este artigo ter apresentado ao leitor as principais bibliotecas digitais disponíveis na internet para pesquisa em ciências humanas, com foco naquelas que apresentam os acervos mais completos em relação às obras mais relevantes da ciência geográfica, mostrado a importância destas plataformas para o desenvolvimento de pesquisas científicas. Agora, caberá ao leitor/pesquisador usufruir destes recursos para melhor embasar suas investigações.

\section{Referências bibliográficas}

BIBLIOTECA DIGITAL ALEMÃ. Catálogo [online]: da biblioteca digital. <https://www.deutsche-digitale-bibliothek.de/>. [Consulta: 30 de novembro de 2020].

BIBLIOTECA DIGITAL HISPÂNICA. Catálogo [online]: da biblioteca digital. <http://www.bne.es/es/Catalogos/BibliotecaDigitalHispanica/Inicio/index.html>. [Consulta: 30 de novembro de 2020].

BIBLIOTECA DIGITAL MUNDIAL. Catálogo [online]: da biblioteca digital. <https://www.wdl.org/pt/>. [Consulta: 30 de novembro de 2020].

FERRETTI, Federico. Élisée Reclus: pour une géographie nouvelle. Paris: Editions du CTHS, 2014. $447 \mathrm{p}$.

GALLICA - BIBLIOTECA NACIONAL DA FRANÇA. Catálogo [online]: da biblioteca digital. <https://gallica.bnf.fr>. [Consulta: 30 de novembro de 2020].

GIBLIN, Béatrice. Élisée Reclus, 1830-1905. Hérodote: revue de géographie et de géopolitique. Paris, $\mathrm{n}^{\circ} 22,1981$, p. 6-13. 
GIBLIN, Béatrice. Élisée Reclus: un géographe d'exception. Hérodote: revue de géographie et de géopolitique. Paris, $\mathrm{n}^{\circ} 117,2005$, p. 11-28.

HAESBAERT, Rogério; PEREIRA, Sergio Nunes; RIBEIRO, Guilherme. Vidal, Vidais: textos de Geografia Humana, Regional e Política. Rio de Janeiro: Bertrand Brasil, 2012. 563 p.

INSTITUTO INTERNACIONAL DE HISTÓRIA SOCIAL. Catálogo [online]: da biblioteca digital. <https://iisg.amsterdam/en>. [Consulta: 30 de novembro de 2020].

NABARRO, Sergio Aparecido. Contribuição à Cronologia de Élisée Reclus. Caderno de Geografia. Belo Horizonte, vol. 30, $\mathrm{n}^{\mathrm{o}}$ 63, 2020, p. 1022-1043. $<$ http://periodicos.pucminas.br/index.php/geografia/article/view/22883>. [Consulta: 30 de novembro de 2020].

PORTAL DOMÍNIO PÚBLICO. Catálogo [online]: da biblioteca digital. <http://www.dominiopublico.gov.br/pesquisa/PesquisaObraForm.jsp>. [Consulta: 30 de novembro de 2020].

PROJETO GUTENBERG. Catálogo [online]: da biblioteca digital. $<$ http://www.gutenberg.org/>. [Consulta: 30 de novembro de 2020].

TERRY, Hervé. As Franjas Pioneiras: de Pierre Monbeig aos nossos dias. In: LEMOS, Amália Inés Geraiges de; GALVANI, Emerson. Geografia, Tradições e Perspectivas: a presença de Pierre Monbeig. São Paulo: CLACSO, Expressão Popular, 2009, p. 49-67.

Ficha bibliográfica:

NABARRO, Sergio Aparecido. Recursos na Internet para pesquisa em Ciências Humanas: as obras fundamentais da geografia. Ar@cne. Revista Electrónica de Recursos en Internet sobre Geografia y Ciencias Sociales. Barcelona: Universidad de Barcelona, I de junio de 2021, vol. XXV, $\mathrm{n}^{\circ} 255$. DOI: https://doi.org/I0.1344/ara202I.255.35329 